\title{
IMITATIO, AEMULATIO, ELOCUTIO: HACIA UNA TIPOLOGÍA \\ DE LAS POÉTICAS DE LA ÉPOCA COLONIAL
}

POR

\author{
Francisco JaVier Cevallos \\ University of Massachusetts
}

Desde los estudios pioneros de Juan María Gutiérrez (1863) y Marcelino Menéndez Pelayo (1911), la vida cultural de la colonia hispana en América se ha ido descubriendo paulatinamente. Nombres como Sor Juana Inés de la Cruz o Juan del Valle Caviedes se han vuelto canónicos en los círculos académicos e intelectuales. Y a partir de la famosa Antología poética en honor a Góngora de Gerardo Diego (1927) el valor de la poesía barroca hispanoamericana ha sido reevaluado, a la par con la del Barroco español. Basta pensar en Domínguez Camargo, rescatado por la Antología mencionada. Así mismo, los estudios ya clásicos de José Toribio Medina (1900, 1904), Guillermo Lohman Villena (1945), e Irving Leonard $(1953,1959,1984)$, entre otros, sirvieron de punto de partida en la tarea de alumbrar la vida intelectual de la época. Las justas y torneos poéticos, el teatro, las disputas científicas, la universidad y la iglesia como centros de la vida social en un mundo cerrado sobre sí mismo, nos dan una idea de la gran riqueza cultural de todo este período de la historia hispanoamericana. Octavio Paz, en su estudio sobre Sor Juana Inés de la Cruz (1982) resume y expone claramente ese mundo y esa vida que constituyen, vistos en panorama, lo que puede llamarse el origen de la "Cultura Hispanoamericana".

Dentro de estos estudios, sin embargo, un enorme y riquísimo campo ha quedado sin explorar. Me refiero al mundo de las teorías sobre la escritura que se produjeron durante esta época, caracterizada por su afán y reflexión sobre el escribir. Ignacio Osorio Romero ha subsanado en parte este vacío al considerar los tratados retóricos escritos en la Nueva España $(1980,1983)$. Pero el campo de la teoría poética está aún sin explorar, en espera de una clasificación o tipología de los numerosos tratados que se escribieron y circularon en ese momento histórico. Es claro que en un trabajo como el nuestro, de carácter introductorio, apenas puede vislumbrarse este gran corpus de escritos, a riesgo de caer en una superficial lista de obras. Lo que este ensayo pretende es ofrecer al interesado caminos que seguir en el estudio de la teoría poética hispanoamericana durante la Colonia.

En primer lugar, debemos bosquejar brevísimamente el problema general de teorías sobre la escritura en el Renacimiento, pues sobre este fondo se escriben todos los textos teóricos coloniales. Debemos recordar ante todo la gran influencia que Aristóteles y sus ideas poéticas y retóricas ejercieron en las actitudes europeas ante el fenómeno de la escritura. La Poética aristotélica, junto a la Epistola a los Pisones de Horacio, eran textos básicos en las discusiones teóricas del Renacimiento. Sin embargo, aceptar esta "autoridad" aristotélica no significaba perder de vista un postulado básico en cualquier indagación científica: el 
conocimiento es progresivo, y no se estanca en una época definida. La gran polémica de "antiguos y modernos" es un resultado directo de esta actitud progresista en relación al conocimiento humano. El Renacimiento fue una época de explosión en el sentido más exacto del término: una necesidad de expansión, de romperse moldes tradicionales, de ampliarse el mundo geográfica, intelectual, filosófica y teológicamente. El Descubrimiento de América y la Reforma protestante son parte de este espíritu expansivo al que aludimos. Seríamos injustos si no reconociéramos ese hálito innovador en las obras retóricas y poéticas de pensadores como Erasmo, Du Bellay, e incluso en los más fieles a la tradición aristotélica, como Nebrija.

Este espíritu encuentra su primer gran representante español en el gran humanista Juan Luis Vives. El argumento primero de Vives en sus estudios sobre De causis corruptarum artium -y que servirá como punto central para toda su argumentación posterior- es que Aristóteles, Quintiliano, Horacio, eran "empíricos" en su observación de las reglas del arte. En palabras de Menéndez Pelayo — cuyo estudio es aún el más completo sobre las ideas literarias españolas-Vives criticaba a los antiguos el haber construido sus obras "no contemplando la verdad cara a cara, sino guiándose por el uso y la observación de las obras creadas, en una materia en que el uso no es señor ni juez" (1943: 148-149). Es decir, postula Vives que el arte tiene una teoría propia, abstracta, que no corresponde necesariamente en su perfección a los modelos de la Antigüedad. Tal aseveración es de importancia fundamental. El acto de escribir, el imitar que toda creación artística supone, se libera de modelos preexistentes, puesto que la ciencia (retórica, poética) que determina tal acto tiene sus propias leyes, inspiradas en la naturaleza y no en los modelos retóricos. Es decir, el poeta es libre de crear no sólo porque los tiempos han cambiado (justificación tradicional en favor de los "modernos"), sino porque la teoría estética es muchísimo más amplia que lo que los "antiguos" habían pensado.

Junto a este postulado primero, se desarrolla en la riquísima teoría literaria de la época otro igualmente original. Me refiero a la aparición del lector (espectador) como integrante fundamental del acto de la creación literaria. Hasta el Renacimiento, la educación se consideraba privilegio de unos pocos, casi siempre dentro de los muros del monasterio o la universidad. Lo que el "vulgo" escuchaba o miraba representarse no era digno de mayor consideración o estima "académica". Con el surgimiento de la burguesía como clase dominante en la vida europea, el papel del "vulgo" cambia radicalmente en la obra artística. Éste es ya un público ciudadano, que se va refinando paulatinamente. El artista siente la necesidad de crear con miras a un "consumo" por parte de su público. La obra de arte deja de perseguir un ideal de belleza o perfección y se orienta a deleitar más que a enseñar, en inversión novedosa del postulado horaciano. Quizás el mejor resumen de este cambio de actitud nos lo da Lope de Vega en su paradójico Arte nuevo de hacer comedias, en el inmortal dístico: "porque, como las paga el vulgo, es justo / hablarle en necio para darle gusto" (1972: 165). Es decir, entre Vives y Lope de Vega se define la libertad de creación artística, a la vez que se asienta que la misma es un objeto de consumo, y que los límites a esta creación no provienen de la retórica o la preceptiva literaria, ya que la misma es eficaz solamente en cuanto es recibida por un público o lector.

Una vez bosquejados estos dos puntos innovadores de la teoría poética española, podemos pasar a la consideración de las ideas literarias en la época colonial. Nuestro trabajo, como aproximación primera a un tema tan amplio, se encuentra limitado en sus 
objetivos. Hemos decidido organizar una especie de taxonomía de las poéticas de la época, como punto de partida para estudios posteriores. Por ello, hemos dividido nuestra selección en tres acápites, siguiendo la pauta propuesta por el título de este estudio: imitatio, aemulatio, elocutio. Las poéticas u obras escogidas son representativas del corpus general, pero la selección de las mismas, claro está, es arbitraria.

Imitatio, aspecto fundamental del proceso de creación artística a partir de Aristóteles, nos sirve para agrupar textos que se dedican a esclarecer de una manera u otra qué es poesía y cuál es la función que ésta tiene en la sociedad. Incluimos estos textos bajo este nombre porque, además de definir de alguna manera la imitación, siguen fielmente modelos retóricos europeos. La idea de imitación es la base para una de las polémicas literarias de la época, es decir, qué se debe imitar. Para esclarecer este punto, los autores se ven obligados a defender el acto de creación poética mediante justificaciones morales. Imitar es también la base para la distinción entre historia y poesía. En este acápite incluimos el Discurso en loor de la poesía, de la anónima poeta peruana "Clarinda", y el Compendio apologético en loor de la poesía de Bernardo de Balbuena, el primer gran teórico de las letras hispanoamericanas.

Bajo aemulatio incluimos tratados que pretenden no solamente explicar qué es poesía o defenderla, sino que nos ofrecen ya una verdadera praxis crítica. Se pretende mejorar a los antiguos, y demostrarlo científicamente mediante comentarios extensos de la obra de los modernos. Por ello, se estudian filológicamente, y a veces con un rigor insospechado, obras de autores contemporáneos, sobre todo la poesía de Góngora, maestro de toda la época. Otra vez, Bernardo de Balbuena es el primer crítico, en el sentido moderno de la palabra, de nuestras letras. Su prólogo a La grandeza mexicana es un interesantísimo comentario crítico sobre su propia creación. Junto a él incluimos a otro gran crítico literario, el famoso Lunarejo, Don Juan de Espinosa Medrano y su Apologético en favor de don Luis de Góngora.

Finalmente, bajo elocutio incluimos los textos que presentan reglas claras y definidas de cómo escribir, es decir, reglas para la producción de textos originales. Son textos de preceptiva literaria o retórica que circularon por colegios y universidades coloniales, $u$ obras generales que dan ideas o sugerencias para la escritura. Otra vez, Balbuena encabeza nuestra lista, con el "Prólogo" a su Bernardo, breve pero compendioso texto de teoría sobre la poesía épica. Incluimos también el Artis Poeticae del jesuita Joaquín Ayllón, libro de texto usado en numerosos colegios de la Compañía de Jesús; y finalmente estudiamos la poética y retórica más original que se escribió en la colonia, y hasta donde sepamos, la más ambiciosa y original de las letras hispanas --el autor específicamente quiere superar la famosa obra de Rengifo--, La Thomasiada del dominico Diego Saénz de Ovecuri, publicada en Guatemala en 1667.

\section{IMITATIO}

Tanto el Compendio apologético en alabanza de la poesía (publicado en 1604) como el Discurso en loor de la poesía (aparecido en 1608) se inscriben dentro de una larga tradición literaria: la defensa y alabanza de la poesía y de los buenos poetas. Pensemos solamente en El viaje del Parnaso de Cervantes, o el difundidísimo Laurel de Apolo de Lope de Vega. La tradición de loa y defensa de la poesía, como señala Robert Ernst 
Curtius (1973: 547-558), es uno más de los topoi literarios del renacimiento y barroco. Así se explica la abundancia de textos en defensa de un género (poesía) que predominaba en las letras de la época. Tanto Balbuena como la desconocida "Clarinda" siguen líneas paralelas en su argumentación y exposición del tema. La diferencia mayor entre los dos textos radica en el hecho de que Balbuena empleó la prosa como su medio de expresión, mientras Clarinda sigue el modelo del terceto encadenado.

Antonio Cornejo Polar (1964) nos da un cuidadoso estudio del Discurso, en el cual traza las fuentes e influencias que configuran el pensamiento de Clarinda. Una de sus conclusiones más importantes es "el hecho comprobado de que Clarinda no estaba retrasada en sus ideas sobre la poesía" (215). Tal aseveración es también aplicable al Compendio de Balbuena, y nos permite, una vez más, apreciar el nivel cultural que en poco más de un siglo habían alcanzado los centros urbanos de la colonia. De hecho, los dos textos que consideramos emplean argumentos similares a los que en Europa daban pie a las grandes polémicas de la época. Veamos en rasgos generales estas ideas.

En primer lugar, la poesía tiene origen divino. Esta idea es claramente de origen platónico, expresada en numerosos diálogos -Ion, Fedro, Banquete-y pasada luego por el tamiz neoplatónico que es tan importante para el pensamiento renacentista. Por ello, la poesía es una forma de aspirar o de subir (en el sentido de Plotino) hacia el mundo divino. De tal manera, Dios es el primer gran poeta y tanto el mundo como el hombre son el gran poema de Dios. Balbuena no duda en llamar al universo "este soneto y compostura del mundo" (1980: 133) y justifica su aseveración con numerosas fuentes clásicas, que le llevan a la tan conocida teoría de la música de las esferas, pues "desde el principio de su creación, crió Dios su capilla de músicos y poetas celestiales ... /que/ le dan y darán eternamente música y alabanzas" (135). Es decir, no es Dios solamente el primer poeta, sino que la poesía le es agradabilísima y los santos y ángeles y el universo todo, giran alrededor de Dios en perfecta armonía. Clarinda, siguiendo esta misma línea, nos dice que Adán fue el primer poeta, pero de todas las ciencias que Dios le dio, la poesía es la única que no puede enseñar a sus descendientes, pues "... este don precioso / solo él, que se los dio, puede otorgallo" (vs. 95-96).

El poeta, pues, es un elegido, y por lo mismo es un ser especial. Clarinda sostiene que "I aquél qu'en todas ciencias no florece, / y en todas artes no es exercitado, / el nombre de Poeta no merece" (vs. 106-108). Balbuena, en líneas semejantes, nos dice que si la poesía tiene defectos, "no es culpa del arte ... sino de los que con flaco talento y caudal la infaman y desacreditan arrojándose a ella sin letras, experiencia y espíritu" (130). Siguiendo los modelos retóricos del tema, ambos autores dan una lista de poetas que autorizan la poesía, tanto bíblicos (David, Salomón, Moisés, etc.) como clásicos (Homero, Horacio, Virgilio, incluso Orfeo). Y los dos autores se ensañan con los malos poetas, quienes son “... malos, suzios, y asquerosos" (vs. 690), y culpables de que la poesía esté desprestigiada. Balbuena, sin embargo, ofrece un punto de gran interés al considerar que "la dignidad y excelencia de la poesía ... será conforme el sujeto que tuviere: divina si fuere divino, honesta y grave si el sujeto fuere grave y honesto, o lasciva, humilde y torpe si tratare cosas tales" (130). Tal actitud está muy cerca a liberar la obra poética de las virtudes del autor. Pero Balbuena, hombre de su tiempo, no puede llegar a una conclusión de esa índole, y a renglón seguido vuelve a subrayar la necesidad de que el poeta sea virtuoso y sabio para poder ser considerado como tal. 
Otro de los temas repetidos en los numerosos tratados de la época es la finalidad de la poesía. El famoso dictum de Horacio sobre deleitar y enseñar (aut prodesse volunt, aut delectare poetae) son la base para toda meditación sobre el fin de la poesía. Clarinda prácticamente traduce el hexámetro: “... su instituto / es deleytar; y doctrinar su oficio" (vs. 290-291), y Balbuena “Al fin, ha sido y es la poesía, desde el principio del mundo, alegría y solaz suyo, tan agradable y dulce que con su deleite armónico concierta el ánima y le entretiene, compone el espíritu, mitiga la ira, alivia los trabajos, acompaña la soledad, ... despierta la virtud, recrea los miembros humanos ... A todos deleita y agrada ... a todos regala y consuela, a todos agrada y levanta el espíritu" (136-137). Para lograr tal fin, el poeta debe no solamente tener inspiración divina, sino además debe conocer cuidadosamente las reglas del arte, pues, según Clarinda, "la vena sin el arte es irrisible" (vs. 312), mientras Balbuena critica que la poesía española sea "pura fuerza de imaginación, sin ir enfrenada y puesta en medida y regla con las que el arte de su facultad pide" (130). La queja de Balbuena es, claro está, parte de un topos repetido hasta la saciedad (recordemos que ésta es la principal queja de Cervantes contra los autores de su época).

Finalmente, para concluir nuestra breve visión de estos dos textos, queremos señalar un punto más de contacto entre los dos autores. Y éste atañe directamente a las letras de la Colonia. Tras las listas acostumbradas de autoridades y fuentes bíblicas, clásicas y españolas, los dos enumeran también poetas de la naciente cultura hispanoamericana. En esto, Clarinda es mucho más generosa que Balbuena, quien se limita a decir "Y en nuestros occidentales mundos" (142) para enumerar solamente a seis poetas mexicanos. Clarinda, por el contrario, nos da una larga lista de autores y autoras coloniales, y no olvidemos que su poema está dedicado a Pedro Mexía de Fernangil, "del Febeo bando / el príncipe” (vs. 802-803). Lo importante de estas dos enumeracionés es la claridad con que aparece una conciencia literaria hispanoamericana, diferente ya, en fecha tan temprana, de la española. Los españoles son dignos de imitación, pero los del "occidental mundo" se hallan ya al mismo nivel poético de creación en la mente de los dos autores. Por eso los versos de Balbuena no son "en el sujeto tan humildes y caídos que no traten de las grandezas de una ciudad ilustre" (146). Tema y estilo marcan ya la "Grandeza" de las nuevas letras. Esta nueva conciencia se desarrollará también en el campo de la preceptiva y teoría literaria, culminando con la obra de Saénz de Ovecuri que estudiaremos más adelante.

\section{AEMULATIO}

Bajo el nombre de imitatio incluimos textos inscritos dentro de una tradición literaria con una larga trayectoria en las letras hispanas. En este segundo acápite vamos a considerar dos textos que se inscriben dentro de otra tradición erudita, pero en este caso mucho más reciente en las letras hispanas. Los textos que vamos a tratar son obras de crítica literaria en un sentido mucho más filológico que la mera apología o alabanza a la poesía. La crítica literaria española, sobre textos hispanos, nace, en verdad, con la obra de Fernando de Herrera, sus Anotaciones (1580) a la obra de Garcilaso de la Vega. Estrictamente hablando, se puede arguir que las Anotaciones (1574) de Francisco Sánchez, el Brocense, al poeta toledano son también un texto de crítica literaria. Sin embargo, los breves comentarios del Brocense se limitan más a señalar el origen de los versos garcilasistas (dentro de una de las múltiples facetas incluidas en el imitatio renacentista) que a ofrecer un comentario crítico 
sobre los mismos. Herrera, por el contrario, en sus extensas anotaciones, va más allá, y señala o destaca el empleo de figuras retóricas, su propiedad, la necesidad del desarrollo técnico del verso, el papel de Garcilaso en la creación de una lengua poética española, e incluso censura el empleo de algunos vocablos que no considera lo suficientemente poéticos. Es decir, estudio filológico de los textos, unido a una apreciación crítica y estética de la obra garcilasista. La novedad de este enfoque - tomado por muchos como ataque directo a Garcilaso por parte de un andaluz - produjo la famosa controversia con el Prete Jacopin estudiada detenidamente por Gallego Morell (1972). Esta disputa literaria es un paso más en el desarrollo de la teoría crítica española. Pocos años después las polémicas se recrudecerán en contra de otro poeta andaluz, Luis de Góngora, y su nuevo lenguaje poético. La escuela teórica que defenderá la poesía culterana en esas disputas tiene ya un precedente erudito y filológico en las Anotaciones de Fernando de Herrera, el Divino.

El año 1604, Bernardo de Balbuena publica su Grandeza mexicana. En ella incluye el "Compendio apologético" ya estudiado, y como prólogo / dedicatoria, incluye una larga "Carta al Doctor Don Antonio de Avila y Cadena, Arcediano de la Nueva Galicia". Veinte y cuatro años después de las Anotaciones de Herrera; Balbuena nos deja el primer texto de crítica literaria de las letras coloniales. No pretendemos exagerar la importancia de la "Carta", ni compararla con la obra de Herrera. La "Carta" de Balbuena no suscitó ninguna polémica ni abrió camino nuevo a la crítica. Sin embargo, es innegable la importancia histórica de la misma en las letras hispanoamericanas.

La "Carta" de Balbuena ofrece un aspecto original que debemos destacar: es un comentario crítico sobre uno de sus propios poemas, unas "Canciones" hechas en honor al arcediano. Aprovecha Balbuena además para incluir otros cuatro poemas de su creación, premiados en diversos certámenes. La carta comienza como glosa explicativa al poema, inscribiéndolo dentro de la tradición italianizante del Renacimiento: "Es todo el Elogio 10 canciones del género demostrativo. Y en la cadencia y orden de los versos imitan la última del Petrarca" (18). El método que sigue a continuación es el mismo empleado por Herrera. Rastrear las fuentes clásicas de cada uno de los versos (y en varias ocasiones vocablos) para mostrar su erudición. Al igual que Herrera, abunda en citas latinas, traducidas por el poeta en verso castellano (ejercicio típico de las clases de retórica de la época). Demuestra, así mismo, su conocimiento de los Emblemata, e incluso menciona el nombre de Alciato y cita el simbolismo que éste le da al laurel. Uno de los momentos más interesantes es su explicación de un neologismo: "Por salas tiberias entiendo el palacio sacro. Y aunque en rigor latino se habrían de decir tiberinas, en el castellano no tuve a mucha licencia sacar tiberias de Tíber, pues de la misma fuente salió Tiberio" (25). Uno de los pasajes más importantes de las Anotaciones de Herrera es su larga defensa de los neologismos. Otra vez, no podemos comparar las cortas líneas de Balbuena con la erudita y extensa disertación herreriana. Sin embargo, sí podemos resaltar que la preocupación con el lenguaje poético es semejante en ambos poetas. Hay que darle riqueza al verso, sonoridad, liberarlo de la pesadez del vocablo trillado, crear un vocabulario nuevo que sea propio de la poesía.

En algunos momentos de la "Carta", Balbuena se preocupa con la preceptiva literaria. Uno de los temas comunes en la preceptiva y poética europea de la época es la posibilidad de escribir poesía sin usar necesariamente el metro o la rima, o incluso hacerlo en prosa. El verso libre no prosperó en la Edad de Oro, aunque hay muchos ejemplos de versos blancos (sin rima) en numerosos poetas, sobre todo en Juan de Jaúregui, quien trató de 
adaptar el verso blanco al repertorio poético español. Dentro de esta línea de pensamiento se inscribe el siguiente comentario de Balbuena: "Porque hay algunos escritores tan dueños y señores de lo que dicen, que hacen de las palabras toda aquella armonía, elegancia y suavidad que quieren; $y$ otros tan sus inferiores y esclavos que las más veces, sin querer ni sentir lo que dicen, arrebatados del furor y fuerza de los consonantes, se hallan donde nunca imaginaron" (18). Es decir, el verso no indica la cualidad poética de la obra - topos renacentista-, pero además los recursos técnicos de la versificación interfieren con el acto mismo de creación poética. Balbuena nos ofrece aquí un comentario crítico de evidente modernidad.

Finalmente, la "Carta" de Balbuena se inscribe además en un espacio geográfico: "Sigue el concepto de la Garza, y como ave amiga de lagunas y riberas frescas, la convida a la juncia mexicana" (24), y este espacio se inscribe, a su vez, dentro de una tradición intelectual que ya ha asimilado: "Esta disgresión, aunque parece algo fuera de intento, todavía no es del todo ociosa que no sirva de apuntar el ordinario ejercicio de la juventud mexicana en todas letras y facultades, y cómo en la poesía puede muy bien competir con Delfos, museo y sagrario de Apolo" (43).

Sesenta años más tarde (1662), en Lima, Don Juan de Espinosa Medrano publica su Apologético en favor de Don Luis de Góngora, en reacción (bastante tardía) a los ataques de Manuel de Faría y Sousa. Éste había incluido numerosos ataques a Góngora en su Comentario a Camôes, llevado de un espíritu nacionalista y de apología de su poeta preferido. Contra esos ataques reacciona el Lunarejo, dejándonos como resultado "la mejor y más ingeniosa poética culterana" según decir de Menéndez Pelayo (350). Cuando Espinosa Medrano escribe su Apologético, en España se ha disipado ya la gran polémica en torno a Góngora, preconizada por Pellicer de Salas y Tovar, Salcedo Coronel, Salazar Mardones, en defensa del culteranismo; y Quevedo, Jaúregui, González de Salas en contra de la obra de Góngora. Esta polémica tuvo un resultado tangencial de gran importancia: los comentarios a la obra de Góngora son verdaderos tratados de teoría y preceptiva poética. El Lunarejo tiene entonces en sus manos la oportunidad de destilar todo ese material, y lo hace de manera única, convincente, en un estilo ameno e irónico, que llevó a Menéndez Pelayo, enemigo declarado del culteranismo, a admitir que el Apologético "es una perla caída en el muladar de la poética culterana" (352). Las investigaciones más recientes sobre teoría poética de la Edad Dorada nos revelan la riqueza de preceptivas y textos críticos de la época (Porqueras-Mayo, 1986). Aun así, el Apologético de Espinosa Medrano continúa siendo una de las poéticas más interesantes del barroco.

El método que sigue el Lunarejo es sumamente eficaz. Cita, en primer lugar, un fragmento de Faría, y a continuación lo refuta irónicamente y con abundancia de erudición. El primer problema que se presenta es el del uso del hipérbaton. Faría, como muchos otros, critica el empleo excesivo de este tropo en la poesía de Góngora. El tema le da pie al Lunarejo no sólo para demostrar la abundancia de hipérbatos en los poetas de la antigüedad y renacimiento, sino que además le sirve para explicar detenidamente qué es el tropo, de dónde proviene, y en cuántas formas se puede clasificar. La Sección IV del Apologético (1982: 35-46) es una verdadera antología de hipérbatos clasificados según el sistema retórico: "Hipérbaton ... Es un traspasamiento en que o la palabra, o la sentencia trueca su orden ... [e] incluye cinco especies ... Anastrophe, Hysteron proteron, Parenthesis, Tmesis, Synchysis" (35). 
La defensa del empleo del hipérbaton en Góngora le lleva a comentar otro fragmento de Faría, en el que el portugués postula que Góngora no es el "inventor" del hipérbaton en lengua castellana, pues ya se había criticado su uso en Juan de Mena y Gómez Manrique. Espinosa arguye que "No inventó Góngora las transposiciones castellanas, inventó el buen parecer, y la hermosura de ellas" (46). Desarrollando su pensamiento, se plantea el problema de antiguos y modernos, una de las polémicas centrales al pensamiento literario de la época. El Lunarejo se manifiesta decididamente en favor de los modernos, "porque falta por decir, que la elocuencia latina tiene mucho que aprender de la gongorina, mucho que imitar de sus primores, mucho que admirar de su espíritu" (51). El problema con el estilo gongorino se halla en la gran cantidad de imitadores incapaces, pues "aquel peregrino ingenio ... fue inimitable" (71). De hecho, quienes intentan imitar al poeta cordobés, tan sólo lo hacen en la forma, sin lograr captar el fondo o espíritu, descubriendo, en un gracioso juego de palabras, no sólo la menoría sino la monería de esos intentos. La idea de la dificultad de imitar a Góngora se basa en la distinción entre fondo y forma (o materia y forma), que explica Espinosa Medrano claramente: "La oratoria y la poesía tienen dos géneros de adorno, uno, que se ha de parte del argumento o de la materia que pertenece a la sentencia; y otro, que se ha de parte del modo de decir que pertenece a la elocución (como si a lo Metafísico dijéramos uno formal y otro objetivo)" (56).

Para concluir esta visión precipitada del Apologético falta por señalar que Espinosa Medrano no se limita a plantear problemas de retórica en su defensa de Góngora. Hay una clara conciencia crítica en su texto, que le permite juzgar no sólo la oba de Góngora, sino la de Tasso, Ariosto, Ovidio, Camôes, Mena, Pedro de Oña (peruano también como el autor) etc., y emitir criterios estéticos sobre los autores y poetas que menciona. Su juicio crítico es ecuánime, y critica a Faría precisamente el que, llevado de su admiración por Camôes, se cegase y echara "a rodar los Virgilios, los Horacios, los Píndaros, los Homeros, los Plautos y Menandros" (68). La obra de Faría se queda en mera apología, mientras la del Lunarejo se vuelve obra de crítica literaria en todo el sentido del término.

\section{ELOCUTIO}

La tercera categoría que hemos seleccionado se refiere a textos que se preocupan de manera directa con el acto de escribir o crear un texto literario. No olvidemos que, después de todo, las reglas del arte eran el centro de las discusiones teóricas de la Edad Dorada. Una vez asentados los postulados básicos de justificación de la obra literaria en base a la utilidad moral o espiritual de la misma, y superado el problema de la imitación (qué y a quién es mejor imitar), queda solamente por delimitar las reglas que se deben seguir en el acto de escribir: el Artis Poeticae o preceptiva literaria que manejaban los poetas. Por su carácter mismo, estas poéticas son de carácter normativo. Su destino, en la mayoría de los casos, era el aula de clase en las escuelas y colegios. Por eso, la gran mayoría de estos textos se encuentran escritos en latín. Así mismo, en muy pocas ocasiones el autor buscaba encontrar nuevas formas de expresión. Antes bien, estos tratados son recopilaciones de reglas establecidas por la tradición retórica, basada en los textos clásicos (Aristóteles, Quintiliano, Cicerón), y muchas veces sus postulados no se ajustan al uso o necesidades del idioma castellano (énfasis en la división acentual sobre la silábica del verso, insistencia en la clasificación abrumadora de imágenes y tropos). 
Otra vez, el primer gran preceptista de las letras coloniales es Bernardo de Balbuena. Su "Prólogo" al Bernardo es un verdadero compendio de las reglas y definiciones de lo que debe ser un poema épico. Por supuesto, la influencia básica en su pensamiento es la Poética de Aristóteles, cuyas ideas sigue cuidadosamente en su exposición. Por ello, el primer punto teórico que debe resolver es el problema de la imitación: "lo que yo aquí escribo es un poema heroico, el cual, según doctrina de Aristóteles, ha de ser imitación de acción humana en alguna persona grave, donde en la palabra imitación se excluye la historia verdadera, que no es sugeto de poesía" (1926: 141). Para Aristóteles, la imitación tenía tres componentes distintos: el medio de imitación (mediante palabras, música, colores y formas), la manera de imitación (verso, prosa, combinación de varios medios) y el objeto o materia de la imitación poética (hombres en acción, héroes o gente común). Para la imitación poética, es necesario contar con el artificio, para distinguir la poesía de la historia. Balbuena sigue la doctrina aristotélica: "hay dos modos de contar y hacer relación de esas mismas cosas [naturales y artificiales], uno natural, que es el histórico, y otro artificial, que es el poético; y así como sería defecto en el discurso natural no comenzar las cosas con claridad, desde sus principios ... así lo sería en el artificial contarlas sin artificio, y como las cuenta el historiador" (141). Por supuesto, no solamente la manera de contar distingue la poesía de la historia, sino la materia que se cuenta. Balbuena sigue la doctrina aristotélica de la verosimilitud, es decir, se prefiere lo imposible probable a lo improbable posible, puesto que "la poesía ha de ser imitación de verdad, pero no la misma verdad, escribiendo las cosas no como sucedieron ... sino como pudieran suceder, dándoles toda la perfección que pueden alcanzar la imaginación del que las finge" (141).

Estos postulados teóricos por parte de Balbuena repiten, más o menos fielmente, los tratados y textos de poética comunes en la época. Aceptadas estas ideas, Balbuena puede esclarecer la escritura de su texto. El tema del mismo, la historia de Bernardo del Carpio, "es sujeto heroico y grave, lleno de honestidad, modestia y pureza del lenguaje" (140). Luego nos aclara que "Y porque la acción ha de ser una, y esa de la persona principal (que llaman épica) la más famosa, escogí la más célebre victoria de Roncesvalles" (140). Pero es aquí, en la "acción única" donde empieza a separarse el Balbuena aristotélico del Balbuena manierista. Su poema comienza en medio de la acción (in medias res) como sugiere Aristóteles, pero "sin dejar por eso de contar su nacimiento y origen, sus hazañas y descendencia, y cuanto dél y de sus sucesores han escrito los historiadores más graves de nuestra nación hasta ochocientos años después de su muerte, con lo más florido de las antigüedades y noblezas de España, descripciones de lugares, montes, ríos y fuentes, castillos y palacios suntuosos, con una universal geografia del mundo, sembrada artificiosamente por él, y las costumbres más notables de sus naciones y aquellas que, por haber dejado vistoso rastro de sí en las memorias de las gentes, mas digné juzgué de ser celebradas" (141). Este tipo de contradicciones entre postulados teóricos y la obra de arte son típicos de la época. Ya hemos mencionado el paradójico "Arte nuevo" de Lope de Vega, ejemplo genial de esta mezcla de respeto por la tradición mientras la obra subvierte los postulados fundamentales de la misma.

Finalmente, Balbuena toca también, aunque brevemente, los problemas de la versificación. Comienza el prólogo asentando que el vulgo presta atención "a sola la armonía de los consonantes" (140), mientras el lector educado se preocupa más por la enseñanza y contenido del poema. Sin embargo, también estos lectores precisan que se les 
sirva "el plato con salsa" (140), que es el arte o artificio. Para conseguir esto, termina el "Prólogo" explicando que "Y porque ser los versos de muchas dicciones y sinalefas, los hace llenos y sonorosos, y el tener pocas, flojos y humildes, y el tener dos asonantes juntos disminuyen la suavidad de las cadencias, y los consonantes en verbales humillan mucho el estilo y le descaecen, se ha huido todo lo posible destas dos cosas" (142). Concluye el "Prólogo" citando un verso del poema, que contiene 14 palabras y 18 sílabas, reducidas a once por la sinalefa: "Que es bien, que es mal, que es fin, que es vida y muerte". La unión de contenido moral y complicación retórica del verso es, para Balbuena, ejemplo supremo del artificio de su obra.

El Padre Joaquín Ayllón nació en la ciudad de Ambato, Ecuador, en 1712. Como tantos otros intelectuales de su época, ingresó en la Compañía de Jesús, donde desempeñó varios cargos académicos. Como los demás jesuitas hispanos de su generación, fue expulsado por la Pragmática de Carlos III en 1767, y fue a Italia, donde continuó su trabajo intelectual hasta su muerte (Batllori, 1966). Mientras enseñaba en el colegio de los jesuitas en Quito, escribió una Artis Poetica y una Retorica que se usaron como textos en varios de los colegios hispanoamericanos. Su Artis Poetica. Compendium, en latín, fue editado por Luis Cordero en 1884, acompañada de una traducción castellana. El texto latino se encuentra lleno de erratas, debidas mayormente a la impericia de los impresores quiteños del siglo pasado en editar textos en latín. Por esa razón, preferimos citar al Padre Ayllón en la traducción castellana.

La Poética de Ayllón no pretende ninguna originalidad en cuanto a la materia que trata. Su intención es solamente orientar a los jóvenes estudiantes en los principios de la versificación. Por eso, no duda en recomendar a sus estudiantes que acudan a otros preceptistas para continuar sus estudios, y especialmente nota que "Acerca del Arte Poética española escribió muy acertadamente Rengifo; y a él debe recurrir todo el que desee consultar ejemplos dignos de ser imitados" (250). Ayllón, como tantos otros preceptistas, sigue el esquema general del Arte poética castellana de Rengifo, incluyendo definiciones básicas, diferentes metros, estrofas, acompañadas de ejemplos. Pero Ayllón nos da solamente un compendio, sin entrar en los detalles abrumadores de la obra de Rengifo.

Veamos en forma breve la Poética de Ayllón. Comienza con la tradicional definición de poesía, "Es el arte de hablar en verso con alguna ficción verosímil" (106), acompañadas de las justificaciones de rigor, siguiendo los postulados de Horacio. Luego explica los elementos necesarios para escribir poesía, y defiende, de manera muy original, que "aquellos sin poseer vena poética bastante fecunda ... [pueden] suplir con la industria y el trabajo" (108-109) esta falta. Este postulado nos permite vislumbrar el papel que jugaba la poesía en la vida diaria de la colonia durante el siglo XVIII. Como señalábamos en la introducción, los torneos y justas poéticas eran parte integrante de la sociedad de la época. El poder escribir en verso, o mejor aún, improvisar en endecasílabos perfectos, eran requisitos para triunfar socialmente. Joaquín Ayllón, hombre de su época, abandona una de las actitudes fundamentales de todo teórico y preceptista anterior, y sostiene que cualquier persona, con un poco de trabajo, puede ser poeta. Para lograrlo, enumera seis condiciones, sacadas de la tradición poética, pero vistas a la luz de su nueva postura ideológica, por lo que la imitación, pasa a último lugar en su lista de prioridades: " $1^{\circ}$, el estudio de las instituciones poéticas; $2^{\circ}$, la lectura de los grandes modelos; $3^{\circ}$, el ejercicio frecuente en componer 
versos ...; $4^{\circ}$, la lima severa, con que se pula una y otra vez la composición; $5^{\circ}$, la posesión a lo menos mediana, de casi toda especie de conocimientos; $6^{\circ}$, la imitación" (109).

Cada uno de estos preceptos ocupa luego un capítulo en que se explica con ejemplos. Lo que es interesante es, siguiendo la actitud mental de Ayllón, la cantidad de restricciones que predica para la composición poética. Si el Lunarejo defendía el uso de neologismos, Ayllón postula que "No deben usarse tampoco voces griegas que no hayan sido empleadas por poetas de reconocido mérito" (123). Si la libertad de creación poética es la base de la defensa del Culteranismo, Ayllón recomienda a sus estudiantes que "observ(en) escrupulosamente" (123) sus preceptos en cuanto al empleo de versos, vocablos, y figuras retóricas.

Un segundo apartado de su obra se dedica a las “especies” de la poesía: epopeya, elegíaca, lírica, bucólica, cómica, trágica, epigramática, y finalmente los tan gustados anagramas, laberintos, etc. Al considerar la poesía lírica, ofrece una larga y cuidadosa enumeración de pies, versos, metros, acompañados de ejemplos. Así mismo, los epigramas y anagramas le permiten demostrar su ingenio de versificador. Lo importante de esta clasificación de los géneros poéticos es el valor que da a la poesía lírica. Es, sin duda, el género que le interesa más, y al que le dedica mayor atención. A pesar de que sigue, originalmente, el patrón clásico de darle mayor valor a la poesía épica -incluso la estudia en primer lugar-, nos ofrece un vislumbre de modernidad prestándole más atención a un género cuya finalidad no es tan "alta" como la heroica. Sus capítulos sobre la poesía lírica, pese a seguir las preceptivas tradicionales en su exposición, apuntan hacia una posible renovación de un género que se encontraba agotado en los numerosos juegos artificiales que saturaban la poesía colonial.

Hemos dejado para último lugar la obra más original de todas las que hemos visto. Aunque precede cronológicamente al tratado de Ayllón, decidimos dejarla como última en nuestro estudio puesto que incorpora todas las ideas expuestas por los preceptistas anteriores. Me refiero al interesantísmo trabajo de Diego Sáenz de Ovecuri, La Thomasiada, al sol de la iglesia y su doctor Santo Thomás de Aquino, impresa en Guatemala por Joseph de Pineda Ybarra, el año 1667 (la censura, aprobación, etc., son de 1664). Este libro es rarísimo, y hemos tenido la suerte de encontrarlo en la Biblioteca de Brown University, quienes generosamente han preparado un "microfilm" del mismo. Sáenz de Ovecuri era un dominico vizcaíno, que vino al Nuevo Mundo temprano en el siglo XVII (Vela, 1960). Su obra, según aclara en su prólogo o "Isagoje a los lectores" (sin foliación), narra la vida de Santo Tomás de Aquino, pero "cuantos han escrito la vida de nuestro santo, la han escrito de una manera, yo la tengo que escribir de muchas, y en muchas diferencias de verso, en 150". Es decir, no sólo se limitará a la hagiografía, sino que "los poetas castellanos, sin necesitar de Rengifo, hallarán en este libro casi toda la teoría y práctica de la poesía". Sáenz de Ovecuri quiere superar a Rengifo, por lo que su obra cumple todos estos propósitos a la vez. Es decir, la obra es una vida de Santo Tomás y a la vez un manual de teoría poética, que resuelve simultáneamente los problemas de versificación planteados con textos originales. Además, las rimas de los poemas están organizadas de modo que, al igual que la obra de Rengifo, pueda utilizarse el texto como un diccionario de rimas. Ovecuri está tan orgulloso de este hecho, que no duda en declarar que "Los romances contienen todas las asonancias posibles", y "De cada diferencia de versos, pongo a lo menos una plana, para que el estudiante no sólo las aprenda, sino las sepa proseguir”. Además, "Aunque el 
libro de Rengifo exceda en mucho al mío, has de confesar por mayores mis desvelos, porque los de aquel son trabajos de otros [poetas] y los míos ejecutados por mí". Una última razón de orgullo es que todo el poema, con sus laberintos, problemas, complicaciones, y curiosidades, le tomó menos de un año componer, escribir y limar cuidadosamente.

El desarrollo de sus ideas teóricas sigue el esquema que hemos visto ya en otros preceptistas. Comienza con la tradicional defensa de la poesía, citando a los mismos poetas clásicos, bíblicos y españoles que citan todos los demás autores coloniales. Luego, al igual que Balbuena, se plantea el problema de la diferencia entre historia y poesía. Es aquí, en esta trillada disputa, donde surge la conciencia hispanoamericana de Ovecuri, que será cada vez más importante en su obra. Para definir poesía, en vez de citar a una de las tradicionales fuentes teóricas, se basa en los tratados del Colegio Mexicano de la Compañía de Jesús: "Es la poesía, dicen estos maestros excelentes de la composición, un arte que finge las acciones de los hombres, y las explica en verso, para componerles la vida en razón de arte. Conviene con las demás, en razón de fingir, etc. Se diferencia, porque las demás artes no fingen, sino que dicen las cosas de la manera que son". Aunque los postulados que sostiene no son originales, es de gran valor el hecho que prefiera usar una autoridad del mundo colonial, en lugar de citar a Aristóteles o alguno de sus comentaristas. A continuación se plantea el problema del verso o la prosa para escribir poesía. Sáenz de Ovecuri rechaza la posibilidad de escribir poesía en prosa, puesto que poesía es "fingir en verso". Para aclarar su punto menciona los Sueños de Quevedo, y especifica que no son poesía, mientras que su Thomasiada "finge versificando, luego este libro es poema".

Pero la gran riqueza de la obra no radica en estas notas que incluye en su introducción al poema. La originalidad de Ovecuri radica en la preceptiva literaria que incluye a continuación, al narrar la vida de Santo Tomás. Se inicia el poema con dos laberintos. El primero una dedicatoria escrita en 22 octavas "que en la primera todos los versos comienzan en A, en la segunda en B, y así las demás, hasta que se acaba el alfabeto". El segundo, que corresponde al Libro I, es una loa al santo. Este laberinto es tan complejo y tan original, que creemos que no tiene comparación en la literatura hispánica. Consta solamente de una página, con cinco columnas de cinco quintillas. Estas columnas pueden leerse verticalmente, horizontalmente, primeros versos, segundos versos, al revés, etc., teniendo siempre rima y sentido. De tal manera, una página contiene muchas páginas, un verso contiene muchos versos. Separada de estas quintillas, se encuentran cinco más, bajo el nombre de "Llabe". Allí se explica la manera en que se resuelve este laberinto, que según Ovecuri, "contiene un libro entero". El mismo Ovecuri advierte que cada lector puede hallar formas nuevas de organizar (leer) el texto: "Mil quintillas hallarás / sobre mil versos, espero". Es un poema que se autogenera, y que depende de la voluntad del lector particular para tener una realización estética.

El Libro II narra el nacimiento, bautizo y niñez del santo. Para hacerlo, emplea 36 diferencias de versos. Ofrece ejemplos de quintillas y décimas de varios patrones métricos, de rima, combinaciones, etc. Lo más original de este libro es su empleo de sonetos de "ocho pies", que acompañacon una nota a los estudiantes: "De la misma manera que el autor inventó este género de versos de sonetos castellanos, puedes tú también inventar octavas, canciones, silvas y cuantos versos hay en italiano". Los siguientes libros ofrecen algunos ejemplos de los problemas técnicos más difíciles de resolver. Por ejemplo, largos romances escritos sin cada una de las cinco vocales, poemas construidos solamente a base 
de palabras esdrújulas, otros solamente de verbos, no faltan las tradicionales glosas a Góngora, y por supuesto abundan todo tipo de laberintos. Todo esto, claro está, con un fondo teológico, hagiográfico, y a veces bibliográfico: incluye un larguísimo "Indice" a las obras de Santo Tomás en endecasílabos asonantados. No vamos a mencionar cada una de las variantes de versos, pues pecaríamos de exceso. Baste con lo señalado para dar una idea general del alcance y complicación del poema de Ovecuri. Finalmente, concluye la obra con una serie de índices, que se organizan en torno a tipos de versos y estrofas, destinados a permitir el uso rápido del poema como texto de referencia. Lo más importante de toda esta serie de laberintos y problemas es que hay una clara conciencia del espacio geográfico en la que se escribe el poema. El mejor resumen de esta actitud la encontramos en una décima "De un íntimo amigo", que se encuentra entre las típicas de alabanza al comienzo del libro:
Yo juzgué que de Madrid
Al Parnaso se subía solo, y que en Madrid había camino a tan docta lid.
Mas en Fray Diego advertid
Cisnes cultos del ocaso
viendo su ligero paso
la industria, el ardor, la gala, que también de Guatemala
se sube al monte parnaso

\section{OBRAS CITADAS}

Ayllón, Joaquín. Artis Poeticae. Compendium. Edición y traducción de Luis Cordero. Quito: Tipografia Gubernamental, 1894.

Balbuena, Bernardo de. "Prólogo" al Bernardo. Edición de Cayetano Rosell en Poemas épicos, volumen XVII de la Biblioteca de Autores Españoles. Madrid: Librería y Casa Editorial Hernando, S.A., 1926. 141.

La grandeza mexicana y Compendio apologético en alabanza de la poesía. Edición de Luis Adolfo Domínguez. México: Editorial Porrúa, 1980.

Batllori, Miguel. La cultura hispano-italiana de los jesuitas expulsos, 1767-1814. Madrid: Editorial Gredos, 1966.

Buck, August. "Doctrinas literarias del Renacimiento y el Barroco". Literatura universal, volúmenes 9-10, a cargo de August Buck. Madrid: Editorial Gredos, 1982. 3978.

Cave, Terence. The Cornucopian Text. Problems of Writing in the French Renaissance. Oxford: Oxford University Press, 1979.

Clarinda. Discurso en loor de la poesía. Estudio y edición de Antonio Cornejo Polar. Lima: Universidad Mayor de San Marcos, 1964.

Curtius, Ernst Robert. European Literatures and the Latin Middle Ages. Traducción de Willard R. Trask. Princeton: Princeton University Press, 1973.

Espinosa Medrano, Juan de, El Lunarejo. Apologético, selección, prólogo, y cronología de Augusto Tamayo Vargas. Caracas: Biblioteca Ayacucho, 1982. 
Gallego Morell, Antonio. Garcilaso de la Vega y sus comentaristas (2 ${ }^{\mathrm{a}}$ edición). Madrid: Editorial Gredos, 1972.

George, Edward V. "Imitatio in the Somnium Vivis". August Buck, editor. Juan Luis Vives. Arbeitsgespräch in der Herzog August Bibliothek Wolfenbüttel. Hamburgo: Dr. Ernst Hauswedell \& Co. 81-92.

Gutiérrez, Juan María. Estudios biográficos y críticos (Buenos Aires: 1863), reimpreso en Escritores coloniales hispanoamericanos, edición, prólogo y notas de Gregorio Weinberg. Buenos Aires: Editorial Raigal, 1957.

Kohut, Karl. "Literaturtheorie und Literaturkritik bei Juan Luis Vives". August Buck, editor. Juan Luis Vives. Arbeitsgespräch in der Herzog August Bibliothek Wolfenbüttel. Hamburgo: Dr. Ernst Hauswedell \& Co., 1981. 35-47.

Leonard, Irving A. Los libros del conquistador. Traducción de Mario Monteforte Toledo. México: Fondo de Cultura Económica, 1953.

Baroque Times in Old Mexico. Ann Arbor: University of Michigan Press, 1959. Don Carlos de Sigüenza y Góngora. Un sabio mexicano del siglo XVII. México: Fondo de Cultura Económica, 1984.

Lohman Villena, Guillermo. El arte dramático en Lima, durante el virreinato. Sevilla: Publicaciones de la Escuela de Estudios Hispanoamericanos de la Universidad de Sevilla, \# 12, 1945.

Martínez Arancón, Ana. La batalla en torno a Góngora. Barcelona: Antoni Boshc Editor, 1978.

Medina, José Toribio. Biblioteca hispanoamericana. Santiago de Chile: Impreso en Casa del Autor, 1900.

La imprenta en algunas ciudades de la América española. Santiago: Impreso en Casa del Autor, 1904.

Estudios sobre literatura colonial de Chile. 2 volúmenes. Edición de Guillermo

Feliú Cruz. Santiago: Fondo Histórico y Bibliográfico José Toribio Medina, 1970.

Menéndez Pelayo, Marcelino. Historia de las ideas estéticas en España. 2 volúmenes.

Buenos Aires: Espasa-Calpe Argentina, 1943. 148-149.

Historia de la poesía Hispano-Americana (1911), 2 volúmenes en Edición nacional de las obras completas de Menéndez Pelayo, volúmenes XVII y XVIII. Madrid: Consejo Superior de Investigaciones Científicas, 1948.

Noreña, Carlos. Juan Luis Vives. La Haya: Maetinus Nijhof, 1970.

Orozco Díaz, Emilio. Lope y Góngora frente a frente. Madrid: Editorial Gredos, 1973.

Osorio Romero, Ignacio. Floresta de gramática, poética y retórica en Nueva España (1521-1767). México: Universidad Nacional Autónoma, 1980.

"La retórica en Nueva España". Dispositio, III (1983): 22-23, 65-86.

Paz, Octavio. Sor Juana Inés de la Cruz o las trampas de la fe. Barcelona: Seix Barral, 1982.

Pierce, Frank. La poesía épica del Siglo de Oro. $2^{\mathrm{a}}$ edición. Madrid: Editorial Gredos, 1968.

Porqueras-Mayo, Alberto. "El 'Arte nuevo' de Lope o la loa dramática a su teatro". Hispanic Review, 53 (1985): 399-414.

La teoría poética en el Renacimiento y Manierismo españoles. Barcelona: Puvill 
Libros, 1986.

Rama, Ángel. "Fundación del manierismo hispanoamericano por Bernardo de Balbuena". The University of Dayton Review, XVI, 2 (1983): 13-22.

Riley, Edward C. Teoria de la novela en Cervantes. Madrid: Taurus, 1981.

Roggiano, Alfredo A. En este aire de América. México: Editorial Cultura, 1966. "Instalación del Barroco hispánico en América: Bernardo de Balbuena". Homage to Irving Leonard. Essays on Hispanic Art, History and Literature. Raquel ChangRodríguez y Donald A. Yates, editores. East Lansing: Michigan State University, Latin American Studies Center, 1977. 61-74.

Van Horne, John. "El Bernardo" de Bernardo de Balbuena. A Study with Particular Attention to its Relations to the Epics of Boiardo and Ariosto and to its Significance in the Spanish Renaissance. Urbana: University of Illinois Press, 1927.

Vega y Carpio, Lope de. (1609). "Arte nuevo de hacer comedias en este tiempo". Federico Sánchez Escribano y Alberto Porqueras-Mayo, Preceptiva dramática española, $2^{\mathrm{a}}$ edición. Madrid: Editorial Gredos, 1972. 154-165.

Vela, David. "La Thomasiada" de Diego Saenz Ovecuri, el mayor alarde retórico en la América Colonial. Guatemala: Editorial del Ministerio de Educación Pública, Colección "José de Pineda Ibarra”, 1960.

Vilanova, Antonio. "Preceptistas de los siglos XVI y XVII". Historia general de las literaturas hispánicas, a cargo de Guillermo Díaz-Plaja, volumen 3. Barcelona: Editorial Barna, S.A., 1953. 567-614.

Vives, Juan Luis. De Disciplinis. Traducción española de Lorenzo Riber. Obras completas. 2 volúmenes. Madrid: Editorial Aguilar, 1948. Volumen 2, 337-398. 
